\title{
Nach bestialischem Mord
}

\section{Todesqual bringt Erben $50.000 €$ Schmerzensgeld}

\begin{abstract}
Das Oberlandesgericht Bremen spricht der Alleinerbin und Mutter eines Mordopfers 50.000 EUR Schmerzensgeld zu. Die Richter gingen davon aus, dass die Agonie des Opfers ins Unermessliche ging.
\end{abstract}

Dauerte der Todeskampf des Opfers eines Gewaltverbrechens eine halbe Stunde lang an und ist mit Sicherheit davon auszugehen, dass es gewaltige Schmerzen und Ängste dabei ausgestanden haben muss, steht den Hinterbliebenen ein erhebliches Schmerzensgeld zu.

\section{Lange Haftstrafe kein Aus für Schmerzensgeldforderung}

Dabei kommt es für die Bemessung des Betrages nicht darauf an, dass der Täter bereits strafrechtlich zu einer langjährigen Haft verurteilt wurde. Vor allem darf die fehlende Leistungsfähigkeit des mittellos einsitzenden Häftlings nicht dazu führen, dass dem Opfer lediglich ein „symbolisches Schmerzensgeld" zuerkannt wird.

Darauf weist die Deutsche Anwaltshotline (DAH) mit Blick auf ein Urteil des Oberlandesgerichts (OLG) Bremen hin. Das OLG sprach der Mutter einer jungen Frau, die mit 28 Jahren bestialisch ermordet wurde, laut DAH ein postmortales Schmerzensgeld in Höhe von 50.000 EUR zu.

\section{Opfer wurde brutal traktiert}

Das Opfer sei zunächst mindestens fünf Minuten lang gewürgt und dann am ganzen Körper, der bei der Obduktion faktisch überall Hämatome und Schürfwunden aufwies, aufs Brutalste traktiert worden - bis zum Eintritt des Todes.

Der alkoholisierte Täter sei inzwischen wegen Mordes und gefährlicher Körperverletzung unter Berücksichtigung verminderter Schuldfähigkeit zu einer Gesamtfreiheitsstrafe von zwölf Jahren verurteilt worden.

Er weigerte sich nun, so die DAH, der Mutter und Alleinerbin des Opfers ein an-

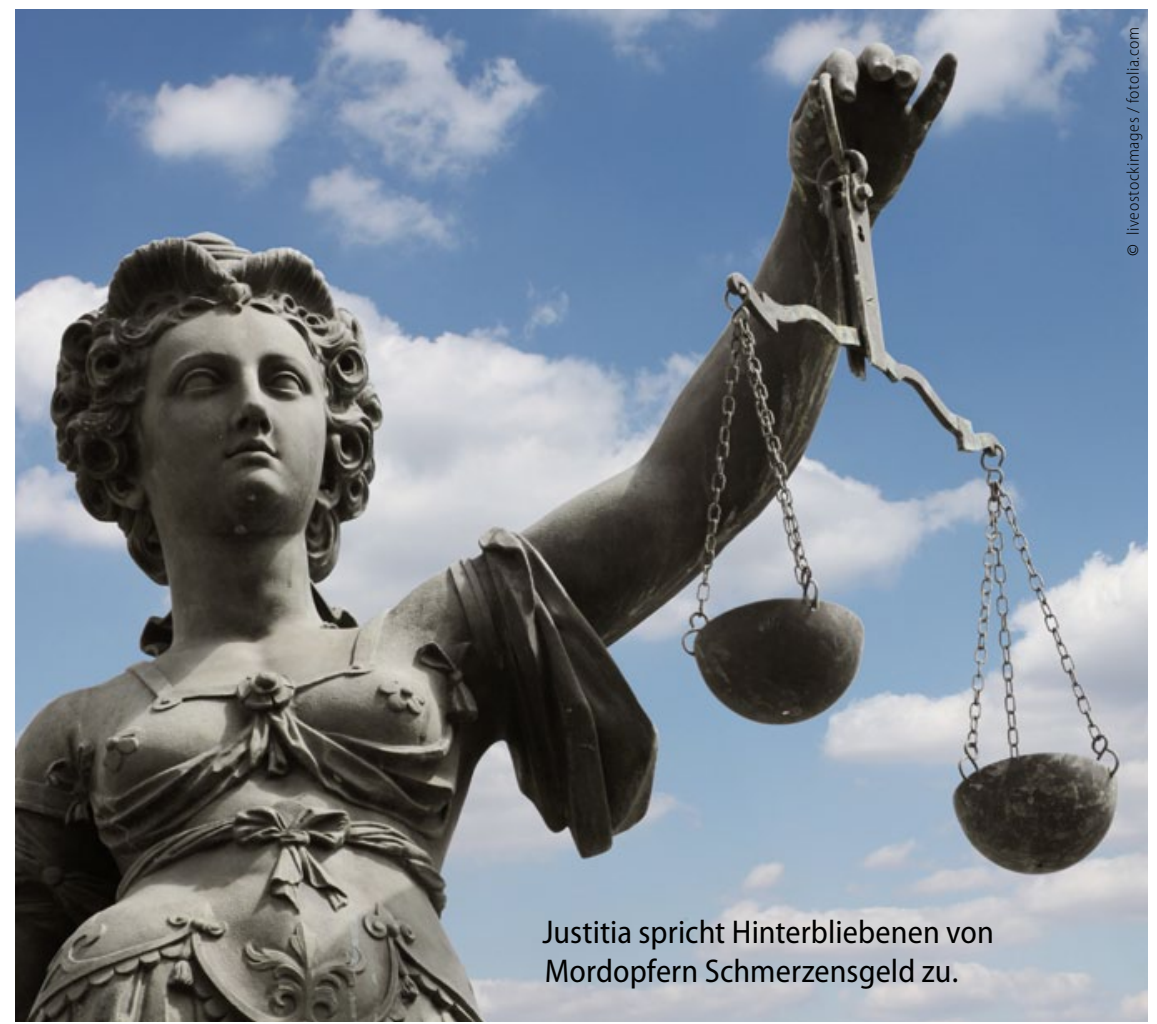

gemessenes Schmerzensgeld zu zahlen, und behauptete, deren Tochter habe nach dem ersten Würgeangriff das Bewusstsein nicht wiedererlangt.

Wer faktisch schon tot sei, wäre aber nicht mehr in der Lage, Schmerzen zu empfinden, für die die Hinterbliebenen eine rechtmäßige Genugtuung verlangen könnten.

\section{Geltendes Gesetz berücksichtigt keine Tötung}

Nach geltendem Gesetz dürfe jedenfalls nur die Körper- und Gesundheitsverletzung, nicht aber die Vernichtung des Lebens als solches Schmerzensgeldansprüche auslösen.

Gegen eine solche Gesetzesauslegung verwahrten sich allerdings die Oberlandesrichter, worauf die DAH hinweist. Laut medizinischem Gutachten sei die malträtierte Frau für einen nennenswer- ten Zeitraum bei vollem Bewusstsein gewesen. Vor allem musste sie in den letzten Minuten ihres schon dahinschwindenden Lebens eine ins Ungeheure gehende Todesangst ausgestanden haben. „Die Kürze dieses letzten Aufbegehrens ihrer Lebenskraft ist dabei angesichts der vorsätzlichen und mit unvorstellbaren Misshandlungen verbundenen Tat kein tauglicher Gradmesser für das Schmerzensgeld“, erklärt DAH-Rechtsanwältin Dr. Sonja Tiedtke.

Hat das Opfer die Verletzungen zwar nur relativ kurze Zeit überlebt, den unausweichlichen Tod dabei aber noch bewusst vor Augen gehabt, rechtfertigt das die $\mathrm{Zu}$ erkennung eines überdurchschnittlich hohen Schmerzensgeldes - weit oberhalb der etwa in der Rechtsprechung bei Verkehrsunfällen üblichen Beträge. (Matthias Wallenfels)

Aerzte Zeitung online, 6.8.2012 